\title{
UTJECAJ PASMINE I SPOLA NA DNEVNI PRIRAST U TESTU SVINJA U PROIZVODNIM UVJETIMA
}

\author{
D. Škorput, A. Vertuš, V. Klišanić, D. Karolyi, Z. Luković
}

\begin{abstract}
Sažetak
Cilj istraživanja bio je utvrditi utjecaj pasmine i spola svinja na dnevni prirast $u$ testu u proizvodnim uvjetima. Istraživanje je obuhvatilo 62469 zapisa iz testa svinja u proizvodnim uvjetima od 1998. do 2017. godine u Republici Hrvatskoj. U istraživanje su bile uključene svinje četiri čiste pasmine: landras (L), veliki jorkšir (VJ), pietren (P), durok (D) te oba recipročna križanca LxVJ. Oba promatrana utjecaja imala su značajan utjecaj $(\mathrm{P}<0,05)$ na dnevni prirast. Uočena je statistički značajna razlika u dnevnom prirastu između pasmina. Prosjeci dobiveni metodom najmanjih kvadrata pokazuju da su svinje pasmine durok imale najveći dnevni prirast sa $583 \mathrm{~g}$, zatim ih slijede križanci LxVJ sa $532 \mathrm{~g}$ i VJxL sa $529 \mathrm{~g}$. Dnevni prirast za velikog jorkšira iznosi $528 \mathrm{~g}$, a najmanji prirast je zabilježen kod pietrena sa $519 \mathrm{~g}$. Utvrđena je značajna razlika $(\mathrm{P}<0,05) \mathrm{u}$ dnevnom prirastu u testu u proizvodnim uvjetima između spolova (nerastića i nazimica) gdje prosječni dnevni prirast dobiven metodom najmanjih kvadrata iznosi 569 g u nerastića i 508 g u nazimica.
\end{abstract}

Ključne riječi: svinja, dnevni prirast, pasmina, križanci, spol

\section{Uvod}

Suvremena svinjogojska proizvodnja zasniva se na korištenju nekoliko pasmina svinja, koje su dugotrajnom selekcijom na ekonomski važna svojstva stekle genetsku osnovu za visoke proizvodne rezultate. Cilj upotrebe plemenitih pasmina svinja je poboljšanje svojstava poput prirasta, konverzije, konformacije trupa te mesnatosti (Virgili i Schivazappa, 2002). Jedan od najvažnijih uzgojnih ciljeva u svinjogojstvu je postizanje brzog rasta svinja kako bi se postigla što ekonomičnija svinjogojska proizvodnja. Selekcija na brži rast svinja provodi se najčešće na temelju podataka iz testa na vlastita svojstva u testnim stanicama ili u proizvodnim uvjetima. Od 2003. selekcija svinja u Hrvatskoj provodi se korištenjem metode mješovitog modela unutar procedure BLUP (Best Linear Undbiased Prediction) (Vincek i sur., 2003), pri čemu se testiranje svinja odvija u proizvodnim uvjetima.

S obzirom da je dnevni prirast srednje nasljedno svojstvo s heritabilitetom od 0,3 do 0,5 (Li i Kennedy, 1994; Chen i sur., 2002), selekcijom se može relativno brzo utjecati na njegovo povećanje. Unatoč srednje visokoj nasljednosti, na uspješnost selekcije utjecat će, osim genetskih čimbenika, i okolišni čimbenici kao što su pasmina i spol svinja u selekciji, hranidba svinja u testu, mikroklimatski uvjeti i zdravstveno stanje svinja.

Doc.dr.sc. Dubravko Škorput, prof.dr.sc. Danijel Karolyi, prof.dr.sc. Zoran Luković - Sveučilište u Zagrebu Agonomski fakultet, Svetošimunska cesta 25, 10000 Zagreb; Andreja Vertuš dipl.ing.agr., Vedran Klišanić, dipl.ing.agr., Hrvatska poljoprivredna agencija, Ilica 101, 10000 Zagreb.

Dopisni autor/Corresponding author: Dubravko Škorput; e-mail: dskorput@agr.hr 
Stoga je cilj rada bio utvrditi razlike između različitih pasmina i križanaca te spola u dnevnom prirastu nerastića i nazimica testiranih u proizvodnim uvjetima

\section{Materijal i metode}

U istraživanju su korišteni podaci koje je ustupila Hrvatska poljoprivredna agencija. Podaci su sadržavali 62469 zapisa iz testa nerastića i nazimica u proizvodnim uvjetima u razdoblju od 1998. do 2017. godine za čiste pasmine, te do 2013. godine za križance. Za pasminu durok podaci su bili dostupni od 2001. godine. U istraživanje su uključene životinje sljedećih pasmina: landras (L), veliki joršir (VJ), pietren (P), durok (D) te križanaca LxVJ te VJxL. Podatkovni zapis sadržavao je informacije o pasmini životinje, sezoni testiranja, vlasniku životinje, tjelesnoj masi, starosti životinje, te debljini slanine, dnevnom prirastu i dobi na kraju testa.

Podaci su analizirani pomoću programskog paketa SAS, V9.4 primjenom procedura MEANS i GLM procedure prema modelu:

$$
y i=\mu+P i+S j+e i j,
$$

gdje je:

$Y_{i}-$ i-ta opažena vrijednost;

$P_{i}$ - fiksni utjecaj i-te pasmine

$S_{j}$ - fiksni utjecaj spola

$e_{i}$ - neprotumačeni utjecaj

Opisna statistika za trajanje testa, tjelesnu masu na kraju testa te dnevni prirast prikazana je u Tablici 1. Najveća fenotipska vrijednost za dnevni prirast izmjerena je u pasmine durok, dok je najniži dnevni prirast u testu izmjeren u križanaca velikog jorkšira i landrasa.

Tablica 1. Opisna statistika za dnevni prirast po pasminama

\begin{tabular}{lccc}
\hline Pasmina & $\mathrm{N}$ & Srednja vrijednost, g & Standardna devijacija, g \\
\hline Landras & 30047 & 521,87 & 69,87 \\
Veliki jorkšir & 11591 & 504,18 & 58,28 \\
Durok & 525 & 569,26 & 73,36 \\
Pietren & 3616 & 516,89 & 73,84 \\
VJxL & 4832 & 499,42 & 44,79 \\
LxVJ & 11858 & 502,08 & 42,36 \\
\hline
\end{tabular}

Prosječne vrijednosti za dnevni prirast $u$ testu u proizvodnim uvjetima bile su više $u$ nerastića nego u nazimica (Tablica 2).

Tablica 2. Opisna statistika za dnevni prirast po spolu

\begin{tabular}{lcc}
\hline Pasmina & Srednja vrijednost, $g$ & Standardna devijacija, $\mathrm{g}$ \\
\hline Nerastići & 566,21 & 66,03 \\
Nazimice & 505,12 & 58,95 \\
\hline
\end{tabular}

\section{Rezultati i rasprava}

Analiza razlika u dnevnom prirastu između pasmina, izraženom kao prosjek sume najmanjih kvadrata, pokazuje da su svinje pasmine durok imale najveći dnevni prirast sa 583 grama, zatim ih slijede križanci LxVJ sa 532 grama i VJxL sa 529 grama. Dnevni prirast za 
pasminu veliki jorkšir iznosi 528 grama, a najmanji dnevni prirast je zabilježen kod pasmine pietren (Tablica 3).

Tablica 3. Utjecaj genotipa na dnevni prirast u testu svinja u proizvodnim uvjetima

\begin{tabular}{lcc}
\hline Pasmina & Dnevni prirast (LS MEAN) & Standardna greška \\
\hline Landras & $0,542_{\mathrm{B}}$ & 0,0004 \\
Veliki jorkšir & $0,528_{\mathrm{A}}$ & 0,0006 \\
Durok & $0,583_{\mathrm{C}}$ & 0,0025 \\
Pietren & $0,519_{\mathrm{D}}$ & 0,0009 \\
VJxL & $0,529_{\mathrm{A}}$ & 0,0006 \\
LxVJ & $0,532_{\mathrm{A}}$ & 0,0009 \\
\hline
\end{tabular}

Rezultati su izraženi kao prosjek sume najmanjih kvadrata \pm standardna greška

Vrijednosti označene različitim slovom su različite na nivou $\mathrm{P}<0.05$

Simić i sur. (2014.) utvrdili su da je brzina rasta u testu također bila najviša kod pasmine durok, a najniža kod pasmine pietren. Dobiveni rezultati odgovaraju rezultatima istraživanja Edwardsa i sur. (2006.). Također, Ball i sur. (1996.) navode da su svinje pasmine durok u testu također imale značajno više dnevne priraste u odnosu na svinje pasmina landras i veliki jorkšir. Križanci s pietrenom u tovu do $100 \mathrm{~kg}$ inferiorniji su u odnosu na ostala dva genotipa svinja, a utvrđen je i negativan utjecaj križanja velikog jorkšira s pietren pasminom na rezultate u tovu (Larzul i sur. 1997.). Razlike između pojedinih pasmina često su posljedica različite ekonomske težine svojstava u selekciji te posljedično različitog selekcijskog pritiska na određeno svojstvo unutar pojedinih uzgojnih programa. Stoga su u različitim istraživanjima uočeni različiti rezultati analiza razlika dnevnog prirasta između pasmina.

Tablica 4. Utjecaj genotipa na dnevni prirast u testu svinja u proizvodnim uvjetima

\begin{tabular}{lcc} 
Spol & Dnevni prirast (LS MEAN) & Standardna greška \\
\hline Muški & $0,569_{\mathrm{A}}$ & 0,0009 \\
Ženski & $0,508_{\mathrm{B}}$ & 0,0006
\end{tabular}

Rezultati su izraženi kao prosjek sume najmanjih kvadrata \pm standardna greška

Vrijednosti označene različitim slovom su različite na nivou $\mathrm{P}<0,05$

Rezultati pokazuju statistički značajnu razliku između spolova gdje je prosječni prirast nerastića iznosio $569 \mathrm{~g}$, dok je za nazimice iznosio $508 \mathrm{~g}$. Razlike u prirastu između spolova možemo pripisati činjenici da nerastići imaju visoki anabolički potencijal uvjetovan interakcijom hormona rasta, inzulin faktora rasta i muških hormona androgena koji djeluju na retenciju dušika i veću sintezu biomase u proizvodnji prirasta (Uremović i Uremović 1996.). Isti autori navode da su muška grla brže postizala tjelesnu masu i imala veće dnevne priraste $u$ odnosu na ženska grla. Također, Latorre i sur. (2003.) navode da muška grla brže postižu veću tjelesnu masu u odnosu na ženska grla te da su razlike statistički značajne. U istraživanju Tadića i sur. (2002.) utvrđen je brži rast muških grla te također prikazani manji utrošak hrane te niža cijena za kilogram prirasta kod nerastića te se tijekom proizvodnje omogućava brže punjenje i pražnjenje objekta gdje su samo muška grla. U istom istraživanju utvrđeno je da su 
muška grla od 56 dana do postizanja tjelesne mase do $100 \mathrm{~kg}$ za kilogram dnevnog prirasta utrošila 3,23 kilograma hrane, dok je za nazimice u tom razdoblju za kilogram prirasta bilo potrebno 3,45 kilograma te je za 0,22 kilograma veći utrošak hrane od nerastića u istom razdoblju.

\section{Zaključak}

Utjecaj pasmine i spola na dnevni prirast u proizvodnim uvjetima je statistički značajan $(\mathrm{P}<0,0001)$. Razlike između pojedinih pasmina $\mathrm{u}$ dnevnom prirastu $\mathrm{u}$ testu svinja $\mathrm{u}$ proizvodnim uvjetima su statistički značajne. Najveći dnevni prirast zabilježen je kod pasmine durok, dok je kod pasmine pietren zabilježen najmanji dnevni prirast. Kod nerastića u testu je uočen značajno veći dnevni prirast u odnosu na nazimice. Prema rezultatima ovog istraživanja može se zaključiti da postoji statistički značajna razlika između spolova (nerastića i nazimica) u dnevnom prirastu svinja u testu u proizvodnim uvjetima.

\section{LITERATURA}

1. Ball, R.O., Gibson, C.A., Aker, K., Nadarajah, B.E., Uttaro, B.E., Fortin, A. (1996.): Differences among breeds, breeds origins and gender for growth, carcass composition and pork quality, Ontario Pork Carcass Appraisal Symposium, pp. 12-20.

2. Ball, R.O. (2000.): Differences among genotype and gender for growth, carcass composition and meat qualitiy. Pork production 11:227:235

3. Chen, P., Baas, T.J., Mabry, J.W., Dekkers, J.C.M., Koehler, K.J. (2002.): Genetic parameters and trends for lean growth rate and its components in U.S. Yorkshire, Duroc, Hampshire, and Landrace pigs. J. Anim. Sci., 80: 2062-2070.

4. Edwards, D.B., Tempelman, R.J., Bates, R.O. (2006.): Evaluation of Duroc-vs. Pietrain pigs for growth and composition. J. Anim. Sci., 84: 266-275.

5. Li, X., Kennedy, B.W. (1994.): Genetic parameters for growth rate and backfat in Canadian Yorkshire, Landrace, Duroc, and Hampshire pigs. J. Anim. Sci., 72: 1450-1454

6. SAS Version 9.4. (2012.). SAS Institute Inc., Cary, NC, USA.

7. Škorput, D., Vincek, D., Luković, Z. (2009.): Fixed effects in models for the genetic evaluation of backfat thickness and time on test in gilts. Italian journal of animal science 8: 119-121.

8. Virgili, R., Schivazappa, C. (2002): Muscle traits for long matured dried meats. Meat science 62: 331-343.

9. Tadić A., Steiner Z., Domaćinović M., Antunović Z., Steiner Z., Lender Z. (2002.). Utjecaj spola i obroka na ekonomičnost tova svinja. Krmiva: Časopis o hranidbi životinja, proizvodnji i tehnologiji krme 44 (5): 229-232.

10. Uremović, M. Uremović, Z. (1996.): Utjecaj spola na proizvodna svojstva svinja. Agronomski glasnik 6: 435-443.

11. Vincek, D., Gorjanc, G., Luković, Z., Malovrh, Š., Poljak, F., Kovač, M. (2003.): Estimation of genetic parameters for time on test and backfat thickness for gilts from field test. Agriculturae Conspectus Scientificus 68, 2/4: 109-113. 


\section{EFFECT OF BREEDS AND SEX ON DAILY GAIN ON PIGS IN FIELD TEST}

\section{Summary}

The aim of the study was to determine the influence of breed and sex on daily gain in field test of pigs. The research included 62,469 data records of pigs in test from 1998 to 2017. Four pure breeds were included in the study: Landrace (L), Large White (LW), Pietrain (P), Duroc (D) and crossbreeds between LxLW and LWxL. Both studied effects had significant effect $(\mathrm{P}<0.05)$ on daily gain. The difference in daily gain between breeds was found to be statistically significant. Duroc pigs had the highest least square means for daily gain rate of $583 \mathrm{~g}$, while least squared means for daily gains were $532 \mathrm{~g}$ and $529 \mathrm{~g}$ for LxLW and LWxL, respectively. The lowest average daily gain of $519 \mathrm{~g}$ was found in Pietrain. The difference in daily gain in field test between the sexes (young boar and gilts) was statistically significant $(\mathrm{P}<0.05)$. The observed least squared means for daily gain were $569 \mathrm{~g}$ and $508 \mathrm{~g}$ for young boars and gilts, respectively.

Key words: pig, daily gain, breed, crossbred, sex

Primljeno - Received: 28.11.2017.

Prihvaćeno - Accepted: 30.01.2018. 